\title{
Pearls \& Oy-sters: Hydroxychloroquine-induced toxic myopathy mimics Pompe disease
}

\section{Critical role of genetic test}

Saurabh Shukla, MD, Sakir "Hume" Gultekin, MD, and Mario Saporta, MD, PhD, MBA

Neurology ${ }^{\circledR}$ 2019;92:e742-e745. doi:10.1212/WNL.0000000000006914
Correspondence

Dr. Saporta

Mas638@med.miami.edu

\section{Pearls}

- Chloroquine and hydroxychloroquine, commonly used for rheumatologic conditions, are rare yet very important causes of toxic myopathy with vacuolar changes on muscle biopsy.

- Pompe disease, a glycogenosis due to deficiency of lysosomal acid $\alpha$-glucosidase (GAA), may sometimes show similar yet less marked changes on muscle histopathology.

- An incorrect diagnosis may lead to frequent, cumbersome, and expensive enzyme replacement therapy when in reality the patient may have an alternate etiology.

- Sporadic and familial inclusion body myositis, myofibrillary myopathy, some forms of limbgirdle muscular dystrophies, and oculopharyngeal muscular dystrophy are some of the other myopathies with rimmed vacuolar changes.

- A dried blood spot test is used as initial screening for Pompe disease. When considering enzyme replacement therapy, confirmatory genetic testing should be encouraged.

\section{Oy-sters}

- Vacuolar myopathy is a nonspecific finding that can be seen in several forms of muscle diseases.

- Absence of respiratory involvement early in the course of illness is atypical for a diagnosis of Pompe disease.

- Genetic testing based on clinical impression often helps to either confirm or refute a previously made diagnosis based solely on muscle biopsy.

- Always assess the actual pathology slides, not just the reports.

\section{Case presentation}

A 65-year-old Caucasian woman presented with insidious onset of symmetric bilateral lower and upper limb weakness, which progressed slowly over the last 3 years. The pattern of weakness was mainly proximal, with some minimal to mild distal weakness evolving in recent months. Weakness was nonfluctuating. She also developed some tingling and numbness in her toes followed by fingertips over the last year. She unintentionally lost 20 pounds since the onset of weakness. No muscle pain, soreness, or swelling was present.

Approximately 3 years ago, the patient had an episode of chest pain lasting several days. This was attributed to pericarditis based on workup at an outside facility. A connective tissue disorder was suspected, and she was started on hydroxychloroquine $200 \mathrm{mg} / \mathrm{d}$. The weakness began insidiously over several months after starting hydroxychloroquine but within that same year. Review of systems was otherwise unremarkable with no difficulty in vision, breathing, speech, or swallow functions. No daytime sleepiness, dryness of mouth, palpitations, rashes, or joint pains were present. No bowel or bladder symptoms, bloating after meals, or impaired 
sweating were present. She takes losartan $100 \mathrm{mg} / \mathrm{d}$ for hypertension. No statins or steroids were used in the past. No alcohol intake was reported.

Neurology examination showed moderate weakness (Medical Research Council grade 4-/5 strength) in neck flexors and proximal limb muscles bilaterally including the deltoids, supraspinatus, infraspinatus, biceps, triceps, iliopsoas, and gluteus maximus. Hip adductor strength was relatively preserved bilaterally $(4+/ 5)$. Ankle dorsiflexors showed mild weakness bilaterally (4/5). Distal limb muscles like toe extensors, intrinsic hand muscles (finger abductors and abductor pollicis brevis), and finger extensors showed minimal weakness bilaterally $(4+/ 5)$. Neck extensors, quadriceps, and wrist and finger flexors were full strength. Tone and bulk were normal. No contractures were present. No grip or percussion myotonia were present. Pinprick was mildly reduced in the toes and fingers and vibration decreased up to the knees. Joint position sense was reduced at the toes bilaterally but preserved at the ankles and fingers. Reflexes were diminished in upper and lower limbs with a flexor plantar response. Romberg test was inconclusive due to patient concerns of fall due to weakness. Otherwise, she had normal vitals, mentation, cranial nerve, and cerebellar examination. Bedside examination did not reveal any evidence of respiratory muscle weakness.

This clinical presentation, combining predominant proximal but also distal weakness, is consistent with a neuromyopathy. The differential diagnosis for this phenotype includes causes of neuromyopathy, including toxic neuromyopathy and neuromyopathy associated with systemic diseases like connective tissue disorders or paraneoplastic, but also neuropathies and myopathies that affect both the proximal and distal limbs. Chronic inflammatory demyelinating polyradiculoneuropathy may present with slowly progressive weakness with a variable degree of proximal or distal muscle involvement, ${ }^{1}$ but would be apparent on nerve conduction studies. Late age at onset was atypical for limb-girdle muscle dystrophy. Absence of fluctuating symptoms was less likely in myasthenia gravis. LambertEaton myasthenic syndrome may lead to nonfluctuating proximal limb weakness and diminished reflexes, but the sensory findings and the absence of dysautonomia (dry mouth, sluggish pupils, or impaired sweating) speak against it. ${ }^{1}$ With no exercise-induced myalgia or weakness, metabolic myopathies were less likely. Rare patients with late-onset McArdle disease may present with progressive proximal muscle weakness and atrophy in late adult life rather than exercise intolerance. ${ }^{2}$ Unlike our patient, these cases were reported to have more weakness in the arms with occasional asymmetry. ${ }^{2}$ Slow progression over 3 years with absence of muscle pain was unlikely in inflammatory or infectious myopathy. Preserved finger flexors and quadriceps strength after 3 years of symptoms was unlikely for inclusion body myositis. Superimposed neuropathy has been reported ${ }^{1}$ in those but is controversial.

As per limited outside records, creatine phosphokinase (CPK) was elevated at 1,203 U/L (normal <200 U/L). Blood urea nitrogen was $9 \mathrm{mg} / \mathrm{dL}(8-23)$ and creatinine $0.58 \mathrm{mg} /$ dL (normal 0.49-1.02) Nerve conduction studies showed preserved sensory responses and no signs of a demyelinating neuropathy. EMG was reported as irritative myopathy in upper and lower limbs.

Left vastus lateralis biopsy from the outside institution described a non-inflammatory vacuolar myopathy with no inclusion bodies. The report also described normal levels of myophosphorylase on histochemical analysis, extensive periodic acid-Schiff (PAS)-positive granular material in vacuolated muscle fibers, and presence of free and membranebound glycogen stores in the vacuolated muscle fibers on electron microscopy.

Based on these findings, the patient had been diagnosed with adult-onset Pompe disease. It was unclear why lysosomal GAA activity was not tested. For the last 6 months prior to our clinic visit, she was on lysosomal GAA enzyme replacement therapy infusions every 2 weeks. It was unclear if this helped the weakness stabilize or led to any objective improvement.

Absence of respiratory weakness despite 3 years of proximal muscle weakness, no specific predilection for lower limb weakness at onset, relatively preserved hip adductor strength, and sensory findings were thought to be atypical of Pompe disease. ${ }^{1}$ A dried blood spot test is a rapid screening test for Pompe disease that assesses GAA activity. ${ }^{1}$ However, as the patient was already on enzyme replacement therapy, we believed this may confound results and hence decided to directly pursue genetic testing. Sequencing of the gene encoding lysosomal GAA did not reveal any variants consistent with Pompe disease and gene panel for limb-girdle muscular dystrophies was also negative.

We reassessed outside pathology slides (figure). In addition to the aforementioned myopathic changes, there were abundant numbers of rimmed vacuoles of various sizes, sometimes multiple vacuoles in the same myofiber, involving both myofiber types. These findings were more marked than what would be expected in adult-onset Pompe disease, where some degree of residual enzyme activity leads to less severe histopathology changes. Unlike in Pompe disease, vacuole contents were nonuniformly PAS-positive. Typical abnormal glycogen deposits, as seen attached to lysosomal membranes or in the cytoplasm, were difficult to identify.

Given the history of long-term hydroxychloroquine use, a toxic myopathy with secondary glycogen and phospholipid accumulation due to acquired lysosomal damage was believed to be the likely etiology. We suggested the patient discontinue hydroxychloroquine and stop enzyme replacement therapy.

Within 9 months of discontinuing hydroxychloroquine, CPK level normalized from 1,200 U/L to $73 \mathrm{U} / \mathrm{L}$. There was no further decline in muscle strength and the sensory symptoms have partially improved. 


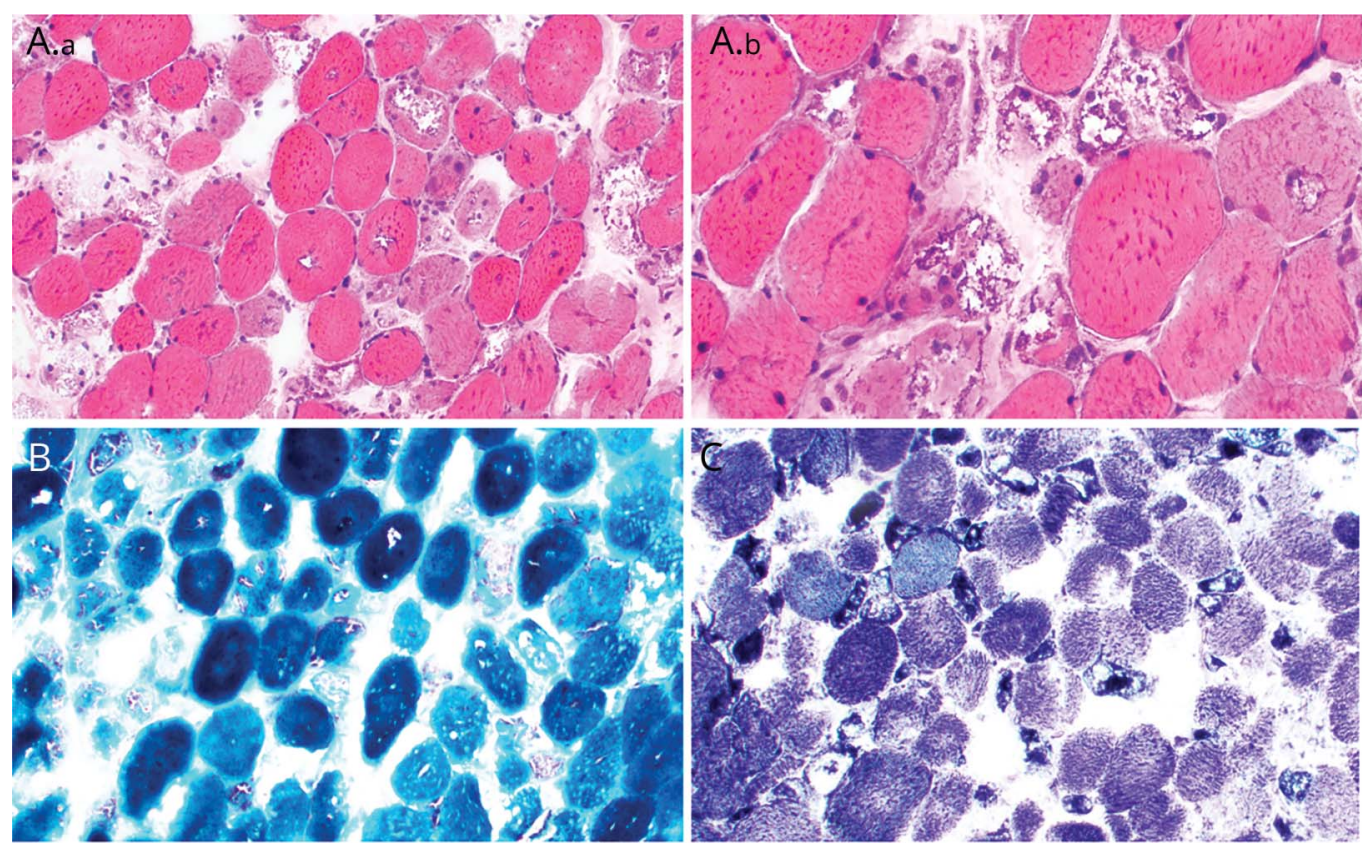

(A) Hematoxylin \& eosin stain: round atrophic fibers, substantial fiber size variation, no inflammation, prominent rimmed vacuoles (magnification: A.a: $\times 200$; A.b: $\times 400$ ). (B) Gomori trichrome: membranous whorls of rimmed vacuoles in type 1 (dark) and type 2 fibers (magnification: $\times 200)$. (C) NADH stain shows central attenuation in scattered myofibers and dark-staining atrophic fibers (magnification: $\times 200$ ).

\section{Discussion}

Hydroxychloroquine and chloroquine are both cationic compounds with high affinity for lysosomes. By reducing the acidic state in lysosomes, they impair its enzyme functions, resulting in inability to fuse and digest several autophagic vacuoles. This can affect several tissues, like skeletal and cardiac muscles, as well as peripheral nerves, leading to myotoxicity or combination of myotoxicity and peripheral nerve toxicity. This is different from the primary inability of lysosomes to catabolize glycogen when GAA is deficient in Pompe disease.

Toxic myopathy from these medications is rare. In one large prospective study of 119 patients, ${ }^{3}$ the annual incidence of toxic myopathy was $1.2 \%$, with a prevalence of $6.7 \%$. Another study estimated the incidence to be 1 in 100 patient-years. ${ }^{4}$

The duration of medication use before symptom onset can be very variable and has been reported anywhere between less than 1 year to more than 10 years. ${ }^{5,6}$ Most studies have reported symptoms at doses of $200-400 \mathrm{mg} / \mathrm{d} .^{3,5,6}$ Our patient was taking $200 \mathrm{mg} / \mathrm{d}$ of hydroxychloroquine and symptoms first began after several months of initiating the medication but within the same year.

The clinical presentation is characterized by progressive symmetrical proximal weakness, which may be associated with mild peripheral neuropathy (neuromyopathy) and cardiac myotoxicity. ${ }^{7}$ Caucasian race and concomitant renal failure are thought to be possible predisposing factors. ${ }^{7}$ Adult- onset Pompe disease, early in its course, has a predilection for hip adductor weakness and respiratory insufficiency. ${ }^{1}$ Neither characterized our patient.

Utilizing muscle enzymes for screening may underestimate myopathy as they may be normal or elevated. ${ }^{8,9}$ Our patient did have a high CPK level of 1,203 U/L. Muscle biopsy demonstrates a rimmed vacuolar myopathy (Pompe disease, on the contrary, is a non-rimmed vacuolar myopathy). Vacuoles are thought to be infrequent in those patients with a short duration of symptoms, typically less than 6 months. ${ }^{4}$ Electron microscopy usually reveals lysosomal proliferation with curvilinear bodies due to phospholipids and glycogen accumulation. ${ }^{7}$ Similar findings have also been demonstrated in neural pericytes ${ }^{5}$ and cardiac myocytes. ${ }^{10}$

Once chloroquine or hydroxychloroquine is discontinued, progression of weakness plateaus in most patients within weeks to months, with improvement in some. A 6-month timeline for clinical improvement is highlighted by one study for those who improve. ${ }^{4}$ For others, resolution is often slow and may not be complete. ${ }^{7}$ In our patient, 4 months after stopping hydroxychloroquine, the progression of weakness stabilized with a substantial drop in creatine kinase levels, which completely normalized by 9 months.

Our case underlines the importance of genetic testing in neuromuscular disorders, especially in those where a time-intensive and expensive novel treatment is to be pursued. It also demonstrates that a toxic myopathy from hydroxychloroquine can 
mimic Pompe disease clinically and pathologically and should be included in the differential diagnosis of patients with limbgirdle weakness and rimmed vacuolar changes on muscle biopsy. In this scenario, a dried blood spot test can be pursued and if positive, followed by genetic testing.

\section{Study funding}

No target funding reported.

\section{Disclosure}

The authors report no disclosures relevant to the manuscript. Go to Neurology.org/ $\mathrm{N}$ for full disclosures.

\begin{tabular}{|c|c|c|c|}
\hline Name & Location & Role & Contribution \\
\hline $\begin{array}{l}\text { Saurabh } \\
\text { Shukla, } \\
\text { MD }\end{array}$ & $\begin{array}{l}\text { University of } \\
\text { Miami Miller } \\
\text { School of } \\
\text { Medicine, FL }\end{array}$ & $\begin{array}{l}\text { Author } \\
\text { (neuromuscular } \\
\text { fellow) }\end{array}$ & $\begin{array}{l}\text { Study concept and } \\
\text { design, acquisition of } \\
\text { data, lead role in } \\
\text { writing manuscript, } \\
\text { analysis and } \\
\text { interpretation }\end{array}$ \\
\hline $\begin{array}{l}\text { Sakir } \\
\text { "Hume" } \\
\text { Gultekin, } \\
\text { MD, FCAP }\end{array}$ & $\begin{array}{l}\text { University of } \\
\text { Miami Miller } \\
\text { School of } \\
\text { Medicine, FL }\end{array}$ & $\begin{array}{l}\text { Author (faculty } \\
\text { mentor) }\end{array}$ & $\begin{array}{l}\text { Acquisition of data, } \\
\text { intellectual } \\
\text { contribution }\end{array}$ \\
\hline $\begin{array}{l}\text { Mario } \\
\text { Saporta, } \\
\text { MD, PhD, } \\
\text { MBA }\end{array}$ & $\begin{array}{l}\text { University of } \\
\text { Miami Miller } \\
\text { School of } \\
\text { Medicine, FL }\end{array}$ & $\begin{array}{l}\text { Senior author } \\
\text { (faculty mentor) }\end{array}$ & $\begin{array}{l}\text { Critical revision of } \\
\text { manuscript for } \\
\text { important } \\
\text { intellectual content, } \\
\text { intellectual } \\
\text { contribution, study } \\
\text { supervision }\end{array}$ \\
\hline
\end{tabular}

\section{References}

1. Amato AA, Russell JA. Neuromuscular Disorders, 2nd ed. New York: McGraw-Hill; 2015.

2. Wolfe GI, Baker NS, Haller RG, Burns DK, Barohn RJ. McArdle's disease presenting with asymmetric, late-onset arm weakness. Muscle Nerve 2000;23: 641-645.

3. Casado E, Gratacos J, Tolosa C, et al. Antimalarial myopathy: an underdiagnosed complication? Prospective longitudinal study of 119 patients. Ann Rheum Dis 2006; 65:385-390.

4. Avtna-Zubieta JA, Johnson ES, Suarez-Almazorj ME, Russell AS. Incidence of myopathy in patients treated with antimalarials: a report of 3 cases and a review of literature. Br J Rheumatol 1995;34:166-170.

5. Estes ML, Ewing-Wilson D, Chou SM, et al. Chloroquine neuromyotoxicity, clinical and pathologic perspective. Am J Med 1987;82:447.

6. Abdel-Hamid H, Oddis CV, Lacomis D. Severe hydroxychloroquine myopathy. Muscle Nerve 2008;38:1206-1210.

7. Stein M, Bell MJ, Ang LC. Hydroxychloroquine neuromyotoxicity. J Rheumatol 2000; 27:2927.

8. Richards AJ. Hydroxychloroquine myopathy. J Rheumatol 1998;25:1642-1643.

9. Siddiqui AK, Huberfeld SI, Weidenheim KM, Einberg KR, Efferen LS. Hydroxychloroquine-induced toxic myopathy causing respiratory failure. Chest 2007; 131:588-590.

10. Ratliff NB, Estes ML, Myles JL, Shirey EK, McMahon JT. Diagnosis of chloroquine cardiomyopathy by endomyocardial biopsy. N Engl J Med 1987;316: 191-193. 


\section{Neurology}

\section{Pearls \& Oy-sters: Hydroxychloroquine-induced toxic myopathy mimics Pompe disease: Critical role of genetic test \\ Saurabh Shukla, Sakir "Hume" Gultekin and Mario Saporta \\ Neurology 2019;92;e742-e745 \\ DOI 10.1212/WNL.0000000000006914}

This information is current as of February 11, 2019

\section{Updated Information \&} Services

References

Permissions \& Licensing

Reprints including high resolution figures, can be found at: http://n.neurology.org/content/92/7/e742.full

This article cites 9 articles, 1 of which you can access for free at: http://n.neurology.org/content/92/7/e742.full\#ref-list-1

Information about reproducing this article in parts (figures,tables) or in its entirety can be found online at:

http://www.neurology.org/about/about_the_journal\#permissions

Information about ordering reprints can be found online:

http://n.neurology.org/subscribers/advertise

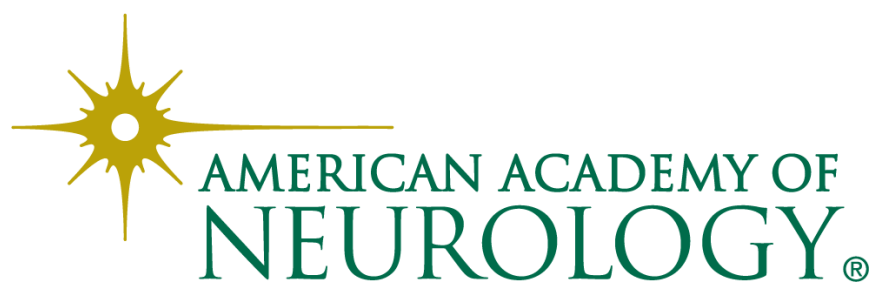

